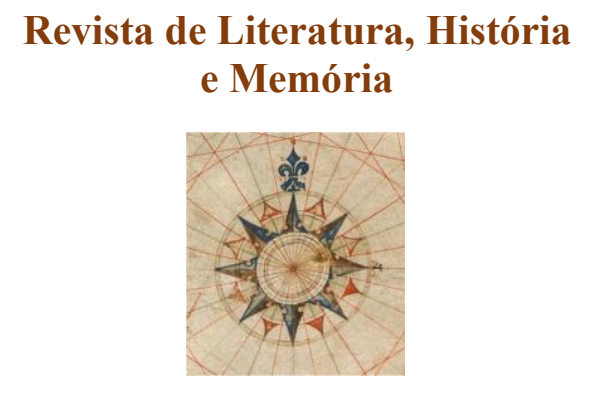

Dossiê: Manifestações de re-existência: a literatura em tempos de repressão

\section{ISSN 1983-1498}

VOL. 16 - $\mathrm{N}^{\circ} 27$ - 2020

U N I O E S T E / CA S C A V E L - p. 141-154

\title{
MEMÓRIA, CONTROLE E HISTÓRIA: UMA ANÁLISE DE NACIÓN VACUNA (2017) DE FERNANDA GARCÍA LAO ${ }^{1}$
}

\author{
Memory, control and history: analysis of Nación vacuna \\ (2017) by Fernanda García Lao
}

\author{
Kelly Luciana Bueno ${ }^{2}$ \\ Antonio Rediver Guizzo ${ }^{3}$
}

RESUMO: Em Nación Vacuna (2017), de Fernanda García Lao, a Argentina se encontra dividida. Dois anos após a vitória da Guerra das Malvinas, os soldados argentinos ainda não podem retornar para casa; antes da retirada da ilha, o inimigo envenenara secretamente as águas. Em razão do envenenamento ter originado uma doença possivelmente contagiosa, os soldados, conhecidos como los envenenados de las $M$, foram obrigados a permanecer isolados na ilha até que uma solução fosse encontrada pelo governo. O enredo de Nación Vacuna centra-se no desenvolvimento de um Projeto, elaborado pela Junta Militar que governa o país, visando à salvação da nação. No desenvolver da trama, observamos a atuação de mecanismos de controle biopolíticos, a manipulação da história e da memória e a declaração de um estado de exceção com o fim de constituir um poder soberano capaz de manipular a verdade e os afetos dos cidadãos e garantir os interesses dos governantes. O objetivo desse artigo é analisar tais questões na obra a partir das perspectivas teóricas de autores como Giorgio Agamben, Michel Foucault, Aleida Assmann e Maurice Halbwachs.

PALAVRAS-CHAVES: Nación Vacuna; Biopolítica; Controle; Memória; Literatura argentina.

\begin{abstract}
In Nación Vacuna (2017), by Fernanda García Lao, Argentina is divided. Two years after the victory of the Falklands War, Argentine soldiers are still unable to return home, since the enemy, before their strategic retreat, secretly poisoned the waters. Because the poisoning caused a possibly contagious disease, the soldiers, known as los envenenados de las $M$, were forced to remain isolated on the island until solution was found by the government. The plot of Nación Vacuna focuses on the development of a project elaborated by the government, aiming at the salvation of the nation. In the development of the plot, we observe the performance of biopolitical control mechanisms, the manipulation of history and memory and the declaration of a state of exception in order to constitute a sovereign power capable of manipulating the truth and the affections of citizens and guaranteeing interests of the government. The aim of this article is to analyze such questions in the work from the theoretical perspectives of authors such as Giorgio Agamben, Michel Foucault, Aleida Assmann and Maurice Halbwachs.
\end{abstract}

KEYWORDS: Nación Vacuna; Biopolitics; Control; Memory; Argentine literature.

\footnotetext{
1 O presente artigo é resultado das pesquisas realizadas no âmbito do projeto de pesquisa Imaginários da Violência na Literatura Latino-Americana, financiado pelo Programa de Infraestrutura para Jovens Pesquisadores - Programa Primeiros Projetos - PPP (Acordo CNPq/Fundação Araucária), e das pesquisas realizadas no Grupo de Pesquisa Imaginários Latino-Americanos (ILA), financiado pelo Programa Institucional de Apoio aos Grupos de Pesquisa da Universidade Federal da Integração Latino Americana (UNILA)

2 Mestranda bolsista da CAPES em Literatura Comparada (PPGLC) pela Universidade Federal da Integração Latino-Americana (UNILA). Membro do projeto de pesquisa "Imaginários da violência na literatura latinoamericana contemporânea". E-mail: kellybbuen@gmail.com

3 Professor do Programa de Pós-Graduação em Literatura Comparada (PPGLC) da Universidade Federal da Integração Latino-Americana (UNILA). Coordenador do projeto de pesquisa "Imaginários da violência na literatura latino-americana contemporânea”. E-mail: antonioredguizzo@gmail.com
} 


\section{INTRODUÇÃO}

Fernanda García Lao nasceu na Argentina em 1966 e atualmente é escritora, dramaturga e poeta. Com mais de uma dezena de livros publicados, pode-se destacar o romance Muerta de hambre (2005), com o qual recebeu o primeiro prêmio do Fundo Nacional das Artes; La perfecta otra cosa (2007) ganhador do terceiro prêmio Cortázar; e Amor invertido (2015), romance escrito em coautoria com o escritor Guillermo Saccomanno. Em 2017, ocorre a publicação de Nación Vacuna, um romance direcionado à discussão de questões como a memória e a história argentina.

Em Nación Vacuna, embora a Argentina supostamente tivesse vencido a guerra das Malvinas em 1982, o país se encontra em um delicado contexto. A estratégica rendição do inimigo e o envenenamento das águas fez com que os poucos soldados argentinos que sobreviveram permanecessem isolados na ilha, e com isso, a Argentina se tornou um país sem defesa. Como a doença causada pelo envenenamento é desconhecida, a possibilidade de contágio faz com que o resgate dos soldados sobreviventes ainda seja inviável. Contudo, um projeto é elaborado com o propósito de salvar a pátria e honrar os soldados argentinos. Dentro da narrativa, portanto, a Argentina é um país em risco, ameaçado constantemente pelos perigos externos. O projeto e todas as medidas necessárias para sua execução fundamentam-se na necessidade de salvar o país, mesmo que para isso seja necessário o sacrifício de alguns para o bem-estar de outros.

O objetivo da análise aqui proposta é investigar os mecanismos de controle presentes na narrativa, e como através desses mecanismos a memória coletiva e a história do país é narrada a partir do desejo do soberano. Para essa análise, serão utilizadas as considerações de Michel Foucault e Giorgio Agamben no que tange a biopolítica e o estado de exceção, e as considerações de Aleida Assmann e Maurice Halbwachs no que diz à respeito às intersecções entre memória e história.

\section{A MEMÓRIA ARGENTINA DE UM PASSADO FANTASMA: APONTAMENTOS INICIAIS SOBRE NACIÓN VACUNA}

Em Nación Vacuna, diferente dos fatos históricos, a Argentina venceu a guerra das Malvinas contra o Reino Unido em 1982. As informações relatadas à população foi que, após a vitória, os soldados não puderam retornar ao país porque as tropas inimigas, antes da retirada, envenenaram as águas da ilha. A população foi informada que, sem suspeitar da 
manobra desonesta do inimigo, também todos os responsáveis pela estratégia militar haviam viajado até as ilhas Malvinas para comemorar juntos aos soldados. A noite foi de festa, com direito a bebidas e mulheres, porém, logo na manhã seguinte, surgiram os primeiros sintomas do envenenamento: contração das pupilas, dificuldade respiratória, náuseas e espasmos. Muitos soldados morreram, alguns entraram em estado de coma e os que continuam vivos apresentam sintomas de distúrbios mentais. Segundo o governo, a possível "doença" é contagiosa, e por esse motivo, resgatar os sobreviventes colocaria em risco toda a nação argentina. Com a ausência de militares, foi necessário formar uma Junta composta por profissionais para governar o país: um ginecologista, um engenheiro e um comissário. A capital argentina é transferida para Rawson, e os militares sobreviventes, que ainda permanecem nas ilhas, são conhecidos pelo povo argentino como os envenenados de las $M$.

O romance é narrado em primeira pessoa e acompanha a vida do protagonista, Jacinto Cifuentes, um funcionário do governo. Toda a história é narrada por sua perspectiva, a partir da qual relata as ações governamentais e a reação da população. Segundo o personagem, por muito tempo a Junta enviava suprimentos para a sobrevivência dos envenenados, no entanto, os mantimentos eram jogados nas costas das ilhas, uma vez que não era possível nenhuma aproximação devido ao risco de contágio. Com o passar do tempo, instalou-se na população a compreensão de que a medida consistia em um desperdício de recursos, e que esse dinheiro poderia ser utilizado em medidas mais urgentes. Grande parte da população foi a favor da decisão, mas um grupo de manifestantes se negou a esquecer dos envenenados de las $M$. Os protestantes foram detidos e os familiares obrigados a entregar todas as fotos dos soldados que haviam ido à guerra, sob punição de multa ou prisão. Ainda assim, a narrativa dos heróis de guerra permanecia como um elo solto que precisava ser gerenciado pelo governo para a manutenção da coesão social.

Quanto ao personagem narrador, à parte os dilemas pessoais, problemas familiares e relações amorosas, Jacinto Cifuentes também trabalha para um importante projeto elaborado pela Junta. O projeto, que possui como lema a salvação da pátria, consiste em selecionar, dentre inúmeras candidatas, mulheres consideradas ideais. Após receberem uma vacina que as protegeria da doença dos envenenados, elas seriam enviadas às ilhas Malvinas com o objetivo de engravidarem dos heróis argentinos e retornar à capital com os filhos como forma de honrar a memória dos vitoriosos soldados. Formado em administração, Jacinto é responsável pela seleção minuciosa das candidatas do projeto e, com o tempo, descobre que faz parte da sua função acompanhar as selecionadas até as ilhas.

Com a seleção finalizada, a tripulação do projeto está formada por quatro mulheres 
selecionadas; três funcionários da Junta; um fotógrafo estatal; dois motoristas e o capitão do "Nación Vacuna", barco que servirá de transporte até o destino final. Em um atentado ocorrido dias antes da viagem, a embarcação que os levaria até a ilha teve o motor furtado por um grupo de manifestantes. Para evitar um novo ataque, o governo decide enviar a equipe de ônibus até a baía Bustamante, onde um novo motor os aguardaria. Em um micro-ônibus, os participantes do projeto são seguidos por um caminhão que transporta o barco.

O estado precário da estrada faz com que o barco balance muito. Para evitar um acidente, o capitão sugere uma parada técnica próxima a um bunker localizado na beira do caminho. Ao entrar em contato com o responsável do governo pelo projeto, a ordem recebida é que apenas o motorista do ônibus vá até a baía e busque o motor do barco e, assim, a equipe poderá continuar a viagem mar adentro a partir daquele ponto. Passado alguns dias e sem o retorno do motorista, a equipe começa a suspeitar do projeto, principalmente porque, ao entrar em contato com o chefe na capital, são informados que o retorno é impossível, uma vez que o governo já anunciou à população que a equipe chegou às ilhas e que as selecionadas já estão tentando engravidar.

Diante da indiferença do governo, a equipe decide elaborar um plano que permite o retorno à capital. Se a nação argentina acredita no sucesso do projeto, a única alternativa é voltar para a capital com uma das mulheres grávidas e dizer que é o filho de um dos soldados envenenados. Para tal fim, Jacinto recebe duas tarefas: construir uma rampa para colocar o barco na água e engravidar uma das mulheres. Tempo depois, duas mulheres estão grávidas e a rampa está pronta. Ao decidir que é hora de retornar a Rawson, a equipe posiciona o barco próximo a água para seguir viagem na manhã seguinte. Contudo, durante a noite, são surpreendidos por uma forte tempestade, e o grupo precisa se abrigar dentro do barco que, com os ventos fortes, é bruscamente arrastado mar adentro. Depois de uma noite à deriva, pela manhã, é possível ver as ilhas Malvinas. Extasiada, a equipe acredita na possibilidade de executar o projeto e retomar suas vidas, porém, ao se aproximarem da ilha, toda a tripulação é surpreendida. O romance termina com a descoberta de que a Argentina não havia vencido a guerra. "Los colores del enemigo ondean sobre el mástil. Perdimos" (GARCÍA LAO, 2017, p. 196).

Embora alguns indícios da narrativa indicam a grande possibilidade de o projeto ser uma farsa, ainda assim a frase final do romance surpreende o leitor. A falsa vitória na guerra, los envenenados de las $M$, o projeto, tudo se refere apenas a mecanismos utilizados para controlar a memória e a história do país.

DESENVOLVENDO OS CONCEITOS DE BIOPOLÍTICA, ESTADO DE EXCEÇÃO E 


\section{HOMO SACER}

Biopolítica é um termo que, segundo Roberto Esposito (2010), foi usado pela primeira vez por Rudolph Kjellen, em 1920, para descrever uma concepção de Estado provido de organicidade própria, isto é: “ideia de Estado, segundo a qual ele não é mais um sujeito de direito nascido de um contrato voluntário, mas um conjunto integrado por homens que se comportam como um único indivíduo ao mesmo tempo espiritual e corpóreo" (ESPOSITO, 2010, p. 23). Michel Foucault, por sua vez, retoma as discussões acerca da biopolítica em sentido diverso, como forma de política moderna que se preocupa com a gestão do corpo social através da regulamentação dos corpos individuais. Mecanismos reguladores que garantem a longevidade humana viabilizando o controle e a promoção da vida de maneira simultânea. A regulamentação dos comportamentos relacionados à longevidade, natalidade, saúde, sexualidade, entre outros, possibilitam o controle da população (FOUCAULT, 1988).

Anos mais tarde, Giorgio Agamben, em sua obra Homo sacer: o poder soberano e a vida nua I (2002), elabora os conceitos de vida nua e homo sacer ao repensar a biopolítica. Para o autor, a biopolítica é uma forma de governo tão antiga quanto a exceção soberana, sendo que, "a produção de um corpo biopolítico seja a contribuição original do poder soberano". (AGAMBEN, 2002, p. 14).

Após Agamben, o italiano Roberto Esposito também desenvolve o tema em seu livro Bios: biopolítica e filosofia (2010). Na obra, o autor admite encontrar na definição de biopolítica um efeito de sentido debilitado e ausente de uma competência interpretativa real, sendo que, somente é clara a definição negativa do conceito - ou seja, aquilo que não é biopolítica. No seu conceito de paradigma da imunização, o filósofo sugere ter encontrado a chave interpretativa que preenche o espaço vazio deixado pelos outros autores, sobretudo, por Foucault. Diferente dos pressupostos relacionados ao conceito de biopolítica, no qual somente em determinados momentos há o encontro entre poder e vida, no seu conceito de imunidade o autor defende que "não existe um poder externo à vida, assim como a vida não se dá nunca fora das relações de poder" (ESPOSITO, 2010, p. 74). Por essa perspectiva, o autor afirma a impossibilidade de existir uma política que não seja uma política da vida.

Em comum no desenvolvimento do conceito, observamos que são diversas e inúmeras as técnicas utilizadas para a dominação dos corpos e o controle das populações. Para Foucault (1988), o poder sobre a vida se desenvolveu em dois pólos: o disciplinar e o regulador. O primeiro, centrado no corpo e seu adestramento, na ampliação ou extorsão de suas forças, e no crescimento de um sujeito ao mesmo tempo útil e dócil. O segundo, concentra-se nos 
processos biológicos desse corpo: natalidade, mortalidade, saúde, longevidade etc. Todos esses fatores são administrados por intervenções e controles reguladores. Se o poder disciplinar tem como foco o corpo individual de cada indivíduo, o poder regulador é ampliado em uma esfera maior: uma "biopolítica de uma população" (FOUCAULT, 1988, p. 130).

Apesar das distintas chaves interpretativas do conceito de biopolítica e de suas particularidades negativas, o que não se logra discutir é que, a partir do momento em que a biopolítica implica múltiplos benefícios, individuais ou coletivos, através de um poder que gere e produz força de vida, ela passa a possuir legitimidade e populariza o "lado positivo do poder" (BOHN; SCHERER, 2015, p. 379). Como a pesquisadora Germana Nascimento ressalta em sua dissertação, o campo da biopolítica abrange o aumento das forças humanas, obtenção de conhecimento, delineamento de modos de agir e pensar, produção de prazeres, etc. Trata-se, portanto, de "uma engenhosa manobra da vida em toda a sua extensão" (NASCIMENTO, 2012, p. 9).

Parece, nesse caso, que a biopolítica é um fator de conservação e ampliação da vida em todas as suas instâncias. Gradativamente, todos os direitos e liberdades individuais são vinculadas ao poder estatal: saúde, moradia, bem-estar, prazer, necessidades etc. Entretanto, devido a sua capacidade de englobar todas as dimensões da vida humana, uma sociedade democrática pode se transformar em um regime totalitário através da biopolítica; isto é, um regime no qual a biopolítica esteja vinculada à dominação total do homem.

Contudo, existe uma linha divisória entre biopolítica e o totalitarismo, que poderia ser traçada entre o direito e a exceção (o estado de exceção). Nas democracias modernas, em face à presença de qualquer ameaça à ordem que se encontra estabelecida em uma sociedade, Agamben (2004) afirma que aquele com o poder de decisão pode suspender temporariamente o ordenamento jurídico, e, através da suspensão da lei, declarar o estado de exceção. Localizado em uma zona de indiferença, entre o caos e a situação normal, no estado de exceção não é mais o direito que normatiza a vida, mas o poder soberano.

Se antes o estado de exceção funcionava como uma suspensão temporária da lei devido a uma situação de perigo, a partir do momento em que se instala como regra, adquire outra posição que o torna permanente, apesar de ainda localizado fora do ordenamento jurídico normal (AGAMBEN, 2002). Com o estado de exceção como regra, o domínio total sobre os homens é possível de ser instaurado. O totalitarismo, portanto, é fruto direto do estado de exceção e se manifesta no momento em que exceção e regra confunde-se em um estado de indistinção (ALMEIDA, 2012).

Com a predominância do estado de exceção em uma sociedade, os habitantes 
encontram-se à mercê de um poder soberano e podem ser despojados de todo estatuto político e jurídico, reduzidos integralmente à vida nua. Em outros termos, transformados em homines sacri - figura do direito romano caracterizada por sua matabilidade e insacrificabilidade -, constituídos de uma vida sem valor, desamparados pelo direito (AGAMBEN, 2002).

Na seção a seguir, pretende-se analisar dentro da narrativa de Nación Vacuna como, em um estado de exceção, o poder é capaz de manipular o indivíduo, a população e a história argentina, mesmo que para isso alguns indivíduos passam a ser homines sacri.

\section{A CONSTRUÇÃO ILUSÓRIA DO PASSADO E A REALIDADE FANTASMA DE NACIÓN VACUNA}

É notório dentro da narrativa de Nación Vacuna diversos elementos de controle aplicado aos indivíduos, fortalecendo a tese de Michel Foucault (1988) sobre a utilização do controle dos corpos individuais para a gestão do corpo social. Mas antes, é necessário compreender que diante de uma Argentina em risco, "ganar las M nos dejó solos. Sin ejército, no somos un país sino un riesgo" (GARCÍA LAO, 2017, p. 44), toda a ordem social está sob ameaça - ameaça que se origina em um inimigo exterior ou pode germinar da própria população.

Declarar o estado de exceção nesse caso é paradoxalmente a decisão de defender a ordem social através de uma vontade soberana que tem o poder de suspender essa mesma ordem (AGAMBEN, 2004). O soberano passa a agir com o poder ilimitado até que a situação volte à normalidade, e poder ilimitado deve ser lido aqui como a possibilidade de exercer qualquer conduta desde que seja sob o pretexto do bem-estar social. Com a interrupção das leis, as liberdades individuais são interrompidas, e o poder soberano - que dentro da narrativa é a figura da Junta Militar - tem a autoridade de decidir sobre a vida dos cidadãos e o futuro argentino.

Embora a Argentina supostamente tenha vencido a guerra, a população vivencia um país em situação de debilidade. A economia está fragilizada e os recursos estão chegando ao fim. Frente à crise, a população é levada a acreditar que salvar os envenenados de las $M$ e recuperar o poder naval é a melhor solução. Quando a Junta informa a suspensão de ajuda aos envenenados de las $M$, grande parte da população também é levada a apoiar a decisão, dessa vez sob o pretexto de que estava sendo um desperdício de recursos que poderiam estar sendo utilizados para reerguer a economia e a saúde do país. Afinal, "El sacrificio de unos pocos bien vale el bienestar general" (GARCÍA LAO, 2017, p. 23). Contudo, houve manifestos 
contra a decisão.

La junta sugirió evitar las conversaciones y las prendas de color verde [...] Los familiares de las víctimas debieron entregar las fotos de los finados, bajo amenaza de multa o cárcel. Se hizo una pira nacional a cielo abierto y cientos de rostros ardieron durante la noche (GARCÍA LAO, 2017, p. 24).

Os manifestos, falhas nos mecanismos ideológicos de convencimento da população, são vistos pela Junta Militar como uma forte ameaça à ordem social, principalmente diante da justificativa de que a Argentina ainda é um país fragilizado. Sob tal argumento, como o país vivencia um estado de exceção, qualquer ameaça à ordem deve ser anulada, mesmo que tal ameaça venha de cidadãos que o Estado teria o dever de proteger, visto que, sob a exceção, todos que se opõem à vontade soberana transformam-se em inimigos. Consoante a Souza (2018, p, 50), “a exceção existe, no Estado de direito, como possibilidade sombria que paira sobre todas as vidas e pessoas que por algum motivo possam ser uma ameaça para a ordem social".

Assim, o controle social exige um controle individual. Em alguns casos, o controle é exercido de forma explícita, como através da existência de uma Manual do bom cidadão.

Al verse solo, papá regaló el contenido completo de la biblioteca. No está bien que un carnicero tenga una, dijo. [...] Según el Manual del Buen Ciudadano, los trabajadores han de mantenerse vírgenes de opinión. El fluir de la consciencia, la libre asociación semántica, son motivo de desconfianza. O de arresto domiciliario (GARCÍA LAO, 2017, p. 27).

O pensamento crítico em relação às decisões do governo é o que se deseja evitar. Foucault (1999) defende que, em uma política voltada à conservação da vida, é necessário, mais do que nunca, a atuação da lei. Não se trata, portanto, de punir com a morte aqueles que a desobedecem, mas sim de distribuir aos cidadãos que as respeitam um sentido de valor e utilidade na sociedade. Devido a isso, o pai de Jacinto não se importa de abdicar-se da leitura ou do pensamento próprio, porque, em troca, ele se sente útil ao seu país. Mas, para que isso funcione, Foucault (1988, p. 134) adverte que "um poder que tem a tarefa de se encarregar da vida terá necessidade de mecanismos contínuos, reguladores e corretivos".

E um desses mecanismos contínuos é a vigilância que ocorre em todas as instâncias da vida. Quando Jacinto rouba da mesa do chefe alguns papéis, ele percebe como até mesmo a vida íntima de todos os funcionários é vigilada e relatada. "Defeco mientras leo datos absurdos sobre metros de papel despilfarrados [...]. Romances entre abogados y 
ascensoristas, magistrados y verdugos. Disfunciones sexuales presentadas con palabrería tosca" (GARCÍA LAO, 2017, p. 41). Uma burocratização da vida íntima, o controle dos corpos e seus costumes.

A vigilância tem o propósito de aniquilar qualquer (possível) ameaça. O tio do protagonista, Evaristo, revela em um jantar que possui informações além do necessário para a realização do seu trabalho dentro do Projeto. No dia seguinte, Jacinto é informado que " $m i$ tío se descompuso" (GARCÍA LAO, 2017, p. 48). A morte repentina do tio e o enterro exageradamente rápido sem a presença de nenhum familiar sugerem a presença e o êxito da vigilância na sociedade. Jacinto sabe que a morte do tio não foi um acidente; sabe que o tio possuía informações confidenciais sobre o projeto; sabe que existe informantes entre eles. Contudo, ele sabe também que o silêncio é a sua melhor alternativa e mostrar qualquer indício de desconfiança em relação a morte do tio pode colocar sua vida em risco.

Em Vigiar e Punir (1987), Foucault analisa a vigilância hierárquica nos acampamentos militares, considerados por ele como o modelo quase ideal do poder disciplinar. Segundo Foucault, a vigilância é uma peça fundamental do poder disciplinar e possui como principal função o adestramento dos corpos - é através do adestramento que ocorre a apropriação total do indivíduo. Por essa razão, a vigilância funciona como uma máquina que distribui os indivíduos em uma estrutura permanente e contínua. Esse tipo de funcionamento é, ao mesmo tempo, indiscreto, pois todos sabem que estão sendo vigiados em qualquer lugar, e discreto, pois "funciona permanentemente e em grande parte em silêncio" (FOUCAULT, 1987, p. 202). No romance, Jacinto tem consciência que a vigilância se enraizou em todos os espaços da vida social e por isso reconhece o peso das palavras. "Yo tampoco opino. Prefiro estar seguro, antes" (GARCÍA LAO, 2017, p. 29).

$\mathrm{Na}$ sequência, a Junta Militar revela ao público o projeto e o objetivo principal. Mulheres estão sendo avaliadas, e as selecionadas - conhecidas como afirmativas - serão vacinadas contra todo o mal e, assim, poderão viajar até as ilhas Malvinas. O objetivo: engravidar dos envenenados de las $M$ e retornar à capital com os filhos dos heróis argentinos no ventre. O projeto é recebido pelo povo com muita euforia, pois segundo o discurso oficial: “Mujeres salvarán al ejército [...] Las mejores hembras, vacunadas contra todo el mal, se prepara para hacer una revolución farmacéutica. Carne nueva. La patria va a levantarse de los escombros [...] Seremos sanos y salvos. Jóvenes, otra vez" (GARCÍA LAO, 2017, p. 77).

Nesse ponto, a escolha narrativa de Fernanda García Lao - principalmente pelo protagonista ser um dos funcionários que atua na linha de frente do projeto - permite que o leitor tenha uma visão diferente da visão da população argentina figurada no romance. Em 
primeiro lugar, as mulheres que participam do projeto são suprimidas de toda sua identidade. Vivem isoladas em quartos individuais; são vigiadas vinte e quatro horas por dia; são despojadas de suas roupas e qualquer acessório pessoal; todas são vestidas de forma igual e passam a ser identificadas por números. "Planes hace entrega de la lista. Las quince mujeres ahora son números (GARCÍA LAO, 2017, p. 37). Não fica explícito dentro da narrativa a obrigatoriedade da participação e nem como as candidatas são escolhidas, no entanto devido aos aspectos dispostos anteriormente, pressupõe-se que a participação dessas mulheres no projeto não ocorre espontaneamente.

Além disso, as mulheres são vistas como meros corpos que precisam estar aptos à reprodução. Tanto que aquela que não é aprovada "se descarta sin concesiones ni opinión al respecto" (GARCÍA LAO, 2017, p. 37). Isto é, são apenas vidas biológicas, cujo valor está intrinsecamente relacionado à capacidade de ser elegida para a missão patriota. Quando alguma candidata não resiste ao processo, parece nem mesmo possuir direito à morte. "Hoy una vacunada muerta. Hubo que sacarla por la porta de trás" (2017, p. 18). As mulheres são taxadas à figura do homo sacer. Isto é, a figura do direito romano abandonada do ordenamento jurídico e, por ser desamparada de qualquer lei, qualquer um poderia matá-lo sem que houvesse punição (AGAMBEN, 2002).

Descartar, segundo a Real Academia Espanhola (2020), significa "excluir o eliminar a alguien o algo". Esse é o verbo utilizado para referir-se às mulheres que não foram selecionadas. Não fica exposto o que de fato ocorre com essas mulheres, no entanto, a narrativa sugere ao leitor uma interpretação dos fatos. Em determinada passagem, Jacinto observa todas as mulheres que foram descartadas subindo em um micro-ônibus azul. "La fila de señoritas que no pasó el Test espera frente a cada puerta" (GARCÍA LAO, 2017, p. 31). Tempo depois, quando visita o pai no frigorífico, encontra um ônibus idêntico estacionado no pátio e, no mesmo dia, o pai afirma que o frigorífico recebeu "un pedido especial para la alimentación de las Hembras por la Patria" (GARCÍA LAO, 2017, p. 114). Jacinto relaciona os dois acontecimentos "me digo que no puede ser. Las descartadas no fueron convertidas en carne para hamburguesa" (GARCÍA LAO, 2017, p. 113). Apesar das fortes suspeitas, a hipótese não é comprovada até o fim da narrativa, contudo, isso reforça a ideia de que para o soberano essas mulheres não possuíam uma vida de valor, como também a ausência de limites do poder soberano.

Chega-se às três finalistas do projeto. $O$ discurso oficial e a importância que as finalistas recebem tanto da mídia quanto da população faz com que outras mulheres, que não foram "convidadas" a participar da seleção, sintam-se excluídas da oportunidade de salvar o 
país e entrar para a história oficial. Para evitar qualquer ameaça e questionamento,

La Junta ha decidido abrir una inscripción pública [...] se fingirá evaluar a las nuevas, aclara. Las candidaturas se entregarán a primera hora de mañana y, una vez completadas, serán puestas en los buzones del correo. Como no hay tiempo de entrevistas, tras su recolección, se elegirá por sorteo a la afortunada [...] La vacunaremos, explica, y la encontraremos apta, más allá de sus condiciones reales. Si no sobrevive, cosa muy probable, será elevada a Ciudadana Ilustre por Decreto (GARCÍA LAO, 2017, p. 78).

Nessa passagem, vê-se claramente as técnicas de manipulação e a discrepante diferença entre a história real e a história oficial que é narrada aos cidadãos.

Já no fim da narrativa, quando a tripulação percebe que o projeto foi uma farsa, ocorre uma expansão dos indivíduos taxados a homines sacri. Se antes apenas as mulheres candidatas possuíam uma vida sem valor, a partir desse momento, todos os envolvidos no projeto e que estão na viagem também têm suas vidas consideradas vidas nuas. Desde as quatro selecionadas à Jacinto e Teodolina (a mão direita do chefe do projeto). Sobre isso,

Nos dois limites extremos do ordenamento, soberano e homo sacer apresentam duas figuras simétricas, que têm a mesma estrutura e são correlatas, no sentido de que o soberano é aquele em relação ao qual todos os homens são homines sacri e homo sacer aquele em relação ao qual todos os homens agem como soberanos (AGAMBEN, 2002, p. 92).

A conclusão evidencia que o poder soberano decide quem permanece dentro e quem está fora do ordenamento jurídico. A qualquer momento, pode ele decidir que determinado indivíduo, possuidor de uma vida politizada e com direitos, pode ter esse valor destituído e ser taxado a homo sacer pela decisão soberana, como aconteceu com toda a equipe do projeto.

A narrativa termina com duas histórias: uma contada ao leitor e a outra à população argentina. Para a população, houve uma guerra, uma vitória, um envenenamento e o esforço do governo em salvar a pátria e os envenenados de las $M$. A verdadeira história, a de que a argentina nunca venceu a guerra, mesmo que descoberta pela equipe do projeto, parece caminhar ao esquecimento, e o governo continuará a exercer um poder soberano, permanecerá controlando a população e reescrevendo a história do país.

Na obra não há somente o controle dos corpos, há também o controle da memória dos cidadãos e, consequentemente, a manipulação da história argentina. Em relação à memória e à história, dois importantes teóricos, Maurice Halbwachs (1990) e Aleida Assmann (2011), demonstram desaprovar a errônea comparação entre os dois conceitos. Halbwachs (1990) 
define a história como um compilado de fatos que ocupam um maior espaço da memória dos indivíduos, contudo, são fatos que foram lidos, ensinados e aprendidos. Ou seja, a história repassa os acontecimentos a partir de uma escolha, aproximação e classificação de um determinado grupo social. Por isso, para ele, a história só é escrita quando a memória social se extingue "Quando a memória de uma sequência de acontecimentos não tem mais por suporte um grupo [...] então o único meio de salvar tais lembranças é fixá-las por escrito em uma narrativa" (1990, p. 80). Nesse sentido, as lembranças e os pensamentos morrem, mas os escritos permanecem.

A manipulação dos fatos que existe em Nación Vacuna não tem como objetivo principal manipular a memória individual ou coletiva, mas sim garantir que a história argentina seja a história escolhida pela Junta Militar. Consoante ao pensamento de Halbwachs (1990), no momento atual da narrativa, embora haja inúmeros funcionários que conheçam a verdadeira história argentina, em um futuro próximo, não haverá mais nenhum sujeito vivo com essa memória, e é nesse momento que a mesma história passará a ser contada, lida e ensinada a partir de uma narrativa. E, no caso, a narrativa da sociedade de Nación Vacuna é a narrativa que através do controle e manipulação vem sendo construída pela Junta Militar que governa o país.

Para o autor, a grande diferença entre memória coletiva e história está no fato de que, enquanto existem inúmeras da primeira, da segunda só existe uma. E a história se fortalece e se torna sólida na medida que as memórias coletivas vivenciadas por grupos se perdem no tempo (HALBWACHS, 1990). Na obra, embora existe uma manipulação da memória, o foco é a manipulação da história que será narrada às futuras gerações.

Nesse sentido, Assmann (2011) sugere a divisão em dois tipos de memória: a memória funcional e a memória cumulativa. A primeira, a memória funcional, relaciona-se a uma memória habitada, que certifica a identidade do grupo, seleciona o que é importante e liga passado e futuro. A memória funcional está vinculada a um portador, ou seja, é a memória de um determinado grupo, instituição, etc. Já a memória cumulativa vincula-se a uma memória inabitada, em que separa passado e futuro, não depende de um portador. Para a memória cumulativa tudo é igualmente importante. É como se a memória funcional de Aleida Asmann (2011) correspondesse à memória coletiva de Halbwachs (1990), enquanto a memória cumulativa à história.

$\mathrm{Na}$ narrativa, é como se a população possuísse a memória funcional. As lembranças estão relacionadas à vivência daquele determinado grupo social - que venceu uma guerra, mas perdeu todo seu poder militar. A memória funcional seleciona o importante - a busca por uma 
solução viável que possa reerguer o país - ao mesmo tempo que relaciona o presente com o futuro - o sucesso do projeto e a salvação da pátria. Através da memória funcional e sua legitimação,

Os dominadores usurpam não apenas o passado, mas também o futuro; querem ser lembrados e, para isso, erigem memoriais em homenagem a seus feitos. Tomam providências para que seus feitos sejam narrados, decantados, eternizados e arquivados em monumentos (ASSMANN, 2011, p. 151).

Por essa razão que a Junta Militar tenta garantir a imortalidade de seus feitos através de cerimônias e fotografias. Existe na obra o Dia da Guerra Ganha, em que bandeirinhas são espalhadas pela população e há uma homenagem aos heróis argentinos. "Se sacan fotos con niños contratados, filman avisos propagandistas impostanto una prosperidad mal actuada" (GARCÍA LAO, 2017, p. 43). Há também a cerimônia com a equipe do projeto ao lado do barco Nación Vacuna. “Un grupo nos ubica frente al casco de acero color naranja. La foto se ocupará mañana las páginas de los principales diarios" (2017, p. 103).

Conclui-se, portanto, que todos os mecanismos de controle, além de garantir a coesão social, também servem para garantir a história oficial do país. A memória coletiva da população, que não possui acesso às informações secretas do projeto, através do controle e manipulação será alinhada aos desejos do governo; enquanto a história oficial vem sendo escrita e reforçada pelos atos públicos registrados e transmitidos pelos meios de comunicação.

\section{CONSIDERAÇÕES FINAIS}

A título de encerramento, compreende-se que todos os mecanismos de controle da narrativa, embora tenham como objetivo garantir a sobrevivência dos cidadãos, têm como maior preocupação a história oficial argentina. As novas gerações, ao procurarem as narrativas do período, encontrarão registros apenas da história criada e narrada pela Junta Militar.

A narrativa demonstra uma crítica social ao representar a manipulação da verdade perpetrada por um governo. Como apontado pela própria história, os Estados e seus governantes continuam, permanentemente, a criar narrativas como forma de controle, principalmente a partir da constituição de medos coletivos, aversão às divergências ou, ainda, da construção de sentimentos patrióticos destituídos de um significado real. Nación Vacuna é, nesse sentido, um romance que constitui uma crítica a essas relações entre Estado, Governo e 
população.

\section{REFERÊNCIAS BIBLIOGRÁFICAS}

AGAMBEN, Giorgio. Estado de exceção. Trad. Iraci D. Poleti. São Paulo: Boitempo, 2004. 2002.

. Homo Sacer: o poder soberano e a vida nua. v. I. Belo Horizonte: Editora UFMG,

ALMEIDA, Davi. Os desdobramentos da biopolítica na contemporaneidade: de Foucault, Arendt e Benjamin a Giorgio Agamben. Textura. Canoas, v. 14, n. 25, 2012. Disponível em: $<$ http://www.periodicos.ulbra.br/index.php/txra/article/view/967>. Acesso em 20 jan. 2020.

ASSMANN, Aleida. Espaços da recordação: formas e transformações da memória cultural. Trad. Paulo Soethe. São Paulo: Unicamp, 2011.

BOHN, Maurício; SCHERER, Marcelo. Biopolítica e meios de comunicação: da naturalização da violência à aos direitos humanos. In: GLOECKNER, Ricardo; FRANÇA, Leandro; RIGON, Bruno (org). Biopolíticas. Curitiba: iEA Academia, 2015. p. 377-391.

ESPOSITO, Roberto. Bios: biopolítica e filosofia. Trad. M. Freitas da Costa. Lisboa: Edições $70,2010$.

FOUCAULT, Michael. História da Sexualidade I: A vontade do saber. Trad. Maria Thereza de Albuquerque. Rio de Janeiro: Edições Graal, 1988. 1987.

. Vigiar e Punir: nascimento da prisão. Trad. Raquel Ramalhete. Petrópolis: Vozes,

GARCÍA LAO, Fernanda. Nación Vacuna. Buenos Aires: Emecé, 2017.

HALBWACHS, Maurice. A memória coletiva. Trad. Laurent Léon Schaffter. São Paulo: Vértice, 1990.

NASCIMENTO, Germana. Nas sombras da contemporaneidade: da biopolítica à tanatopolítica. Dissertação apresentada ao Programa de Pós-graduação em Filosofia. Universidade Federal de Pernambuco. Recife, 2012. Disponível em $<$ https://repositorio.ufpe.br/bitstream/123456789/10660/1/Germana dissert.pdf $>$. Acesso em 05 jan. 2020.

REAL ACADEMIA ESPAÑOLA: Diccionario de la lengua española, 23. ed., [versión 23.3 en línea]. Disponível em: $<$ https://dle.rae.es $>$ Acesso em 07 jul. 2020.

SOUZA, Danigui. Estado de exceção: Giorgio Agamben entre Walter Benjamin e Carl Schmitt. Princípios. Rio Grande do Norte, v. 25, n. 47, p. 35-58, 4 jun. 2018. Disponível em

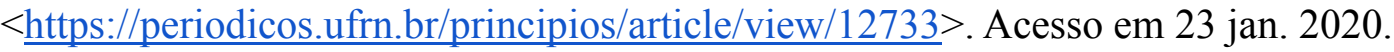

